\title{
The Influence of Strain Path on Rare Earth Recrystallization Textures in a Magnesium-Zinc-Rare Earth Alloy
}

\author{
D. GRIFFITHS, B. DAVIS, and J.D. ROBSON
}

\begin{abstract}
In this study, the effect of strain path on texture evolution during cold rolled and annealing of hot rolled Mg-Zn-Rare-Earth (RE) alloy (ZEK100) sheet has been investigated. Strain path during cold rolling has been varied by changing rolling direction with respect to the original hot rolling (HR) direction of the sheet. Cold rolling either parallel or perpendicular to the HR direction leads to spread and split of basal poles in the transverse direction (TD) during annealing, characteristic of Mg-Zn-RE alloys. However, when the sheet is continuously rotated between cold rolling passes, this texture spread is not produced. It is demonstrated that a change in dislocation activity, as predicted by crystal plasticity modeling, cannot explain the unusual textures developed in $\mathrm{Mg}-\mathrm{Zn}-\mathrm{RE}$ alloys. Instead, the role of strain path in determining shear band evolution is considered to be critical. When shear bands are suppressed by continuously rotating the specimen, the distinct $\mathrm{Zn}-\mathrm{RE}$ texture is not produced. Furthermore, it is demonstrated the dominance of the TD spread grains emerges gradually during recrystallization, leading to the final observed texture.
\end{abstract}

https://doi.org/10.1007/s11661-017-4404-3

(c) The Author(s) 2017. This article is an open access publication

\section{INTRODUCTION}

IN recent years, there has been renewed interest in wrought magnesium alloys as part of the drive to reduce weight and hence produce greener, more fuel efficient vehicles. ${ }^{[1]}$ The two primary limitations preventing the widespread uptake of magnesium alloys are low formability and poor corrosion performance.

This study focuses on the first aspect, where there has been considerable research effort to extend the formability of magnesium alloy to sheet to lower temperatures, so that it becomes a commercially viable material for mass produced vehicle manufacture. To achieve this goal, two main approaches are followed, which involve either adjusting processing route or changing alloy chemistry.

The discovery that small additions of rare earth (RE) elements can significantly enhance formability has led to an intense focus on these alloys. ${ }^{[2,3]}$ Although there has been considerable progress in understanding the role

D. GRIFFITHS is with the TWI Ltd, Granta Park, Cambridge, CB21 6AL, UK. B. DAVIS is with the Magnesium Elektron North America Inc., 1001 College St., P.O. Box 258, Madison, IL 62060. J.D. ROBSON is with School of Materials, University of Manchester, MSS Tower, Manchester M13 9PL, UK. Contact e-mail: joseph.d.robson@manchester.ac.uk

Manuscript submitted February 2, 2017.

Article published online November 22, 2017 that RE plays in producing this enhancement, a complete explanation for all the observed effects remains elusive. This is partly because RE additions have a complex influence on several microstructural mechanisms that ultimately control formability, and it is a combination of these effects that appears to give the desirable macroscopic behavior. However, it is clear that the effect of RE in weakening or changing the texture in $\mathrm{Mg}$ sheet is central to its effectiveness in improving formability. The origins of this texture change are themselves complex. Increased non-basal slip, a change in twining activity, changes in the size and distribution of shear bands, and modification of the dynamic and static recrystallization behavior have all been cited as important texture modifying mechanisms. ${ }^{[4]}$ Furthermore, there is now good evidence that the strong segregation of RE to sites such as grain boundaries or dislocations helps explain why even very low levels of addition $\left(<0.1 \mathrm{wt}\right.$ pct in some cases) can be effective. ${ }^{[5-8]}$ These mechanisms have been summarized in a recent review. ${ }^{[9]}$

While weak RE textures in magnesium alloys have been studied for some time, it has only recently been appreciated that tertiary alloying additions such as $\mathrm{Zn}$ can produce a significantly different texture (referred to here as the $\mathrm{Zn}-\mathrm{RE}$ texture). RE textures in rolled $\mathrm{Mg}-\mathrm{RE}$ binary alloys are best described as weak deformation textures. ${ }^{[2]}$ In rolled sheet, such textures are usually characterized by a spread or split in basal poles toward the rolling direction (RD). This type of 
texture is seen in both RE and non-RE containing rolled sheet, the effect of RE being to weaken the texture but to retain an RD spread in basal poles. ${ }^{[2]}$

$\mathrm{Mg}-\mathrm{Zn}$-RE (ZE) alloys recrystallize after rolling to produce a different and characteristic texture in which the basal poles are split toward the transverse direction (TD) of the sheet. This unique TD spread texture has been observed in a variety of magnesium-Zn-RE alloys including those containing $\mathrm{Ce}, \mathrm{Gd}$, and $\mathrm{Nd}^{[4,10-13]}$ Similar textures have been observed in alloys which contain $\mathrm{Ca}$ rather than $\mathrm{RE} .^{[10]}$ In the as-rolled condition (hot rolling) such materials often show a spread in basal poles toward the TD, even if a split toward the RD is retained. ${ }^{[4,12,13]}$ The pronounced spread and split toward the TD emerges during recrystallization. These alloys have attracted considerable interest because the textures produced give greatly improved formability over conventional (non-RE) $\mathrm{Mg}$ alloy and binary $\mathrm{Mg}-\mathrm{RE}$ sheet.4,14]

Given the apparently similar behavior exhibited in $\mathrm{Mg}-\mathrm{Zn}-\mathrm{RE}$ and $\mathrm{Mg}-\mathrm{Zn}-\mathrm{Ca}$ sheet with regard to texture and formability, it is reasonable to consider studies of both types of material together, notwithstanding the differences between $\mathrm{Ca}$ and RE (and also between different RE additions). The effectiveness of REs in magnesium is attributed to their large atomic size (and associated mismatch with magnesium), sluggish diffusion, and effect on stacking fault energy. It is argued that $\mathrm{Ca}$ behaves similarly since it shares these attributes. ${ }^{[10]} \mathrm{A}$ small number of studies have attempted to understand the development of texture in $\mathrm{Mg}-\mathrm{Zn}-(\mathrm{RE}, \mathrm{Ca})$ alloys during deformation ${ }^{[4,10,15]}$ and annealing. ${ }^{[4,10]}$

During cold deformation, it has been argued ${ }^{[15]}$ that twinning dominates texture evolution, and the main effect of combined additions (of $\mathrm{Ca}$ and $\mathrm{Zn}$ ) is to suppress twin growth, leading to a lower twin fraction (for a given applied strain) and nucleation of more twin variants within a grain. This is claimed to be responsible for the weaker texture in such alloys. ${ }^{[15]}$

The importance of recrystallization (after warm rolling) in producing the characteristic TD spread in $\mathrm{Mg}-\mathrm{Zn}-(\mathrm{Ca}, \mathrm{RE})$ rolled sheet has been noted in several studies. $^{[4,10,12,13]}$ It has been observed that during recovery and recrystallization, TD-oriented grains appear more resistant to recrystallization, whereas those with basal poles spread (or split) toward the rolling direction (RD) are consumed, leading to dominance of the TD spread grains. The TD spread grains are seen to emerge from shear bands in the material. ${ }^{[10,13]}$

A factor that has yet to receive much attention is the role of the strain path in determining the final texture. Changes in strain path will change both dislocation activity and shear band behavior and this provides one way to explore the key factors in the deformed structure in determining the evolution of the unusual and desirable TD texture spread. In the present paper, cold rolling followed by static recrystallization has been performed on hot rolled sheet of ZEK100, a Mg-Zn-Nd-Zr alloy. Rolling has been carried out following a number of different strain paths, with the aim of changing dislocation and shear band activity to study the effect this has on texture evolution after both deformation and subsequent annealing.

\section{EXPERIMENTAL}

The material in this investigation is a commercial hot rolled and fully recrystallized ZEK100 sheet (nominal composition $\mathrm{Mg}-1.3$ wt pet $\mathrm{Zn}-0.2$ wt pet $\mathrm{Nd}-0.3$ wt pet Zr) supplied by Magnesium Elektron North America. This material has a texture typical of Mg-Zn-RE sheet, with a spread in the basal poles toward the TD, as demonstrated later.

Three cold rolling processes, involving 9 to 11 passes, were carried out on this sheet: straight cold rolling (SCR), where the cold rolling direction $\left(\mathrm{RD}_{\mathrm{CR}}\right)$ is parallel to the hot rolling direction $\left(\mathrm{RD}_{\mathrm{HR}}\right)$ of the sheet, transverse cold rolling (TCR), where the $\mathrm{RD}_{\mathrm{CR}}$ is perpendicular to the hot rolling direction, and finally equal cold rolling (ECR) where an equal amount of strain is imparted parallel and perpendicular to the $\mathrm{RD}_{\mathrm{HR}}$ with multiple rotations of the sheet. A schematic of the SCR, TCR, and ECR processes is presented in Figure 1 and the rolling schedules are presented in Tables I and II. All rolling was carried out at roll speed of $6 \mathrm{~m} / \mathrm{min}$ on a laboratory mill with a target reduction of $0.2 \mathrm{~mm}$ in each pass.

A blank was rolled to failure according to each schedule and the specimens used in this study were subjected to two fewer passes than the failed blank. As such the total strains in each orientation are close to the maximum achievable before failure. ECR was carried out by rotating the specimen by $+90 \mathrm{deg}$ followed by $90 \mathrm{deg}$ on the following pass. Following rolling, the material was fully recrystallized by annealing at $673 \mathrm{~K}$ $\left(400{ }^{\circ} \mathrm{C}\right)$. Static recrystallization $(\mathrm{SRX})$ in the TCR material was investigated in detail by EBSD after annealing as-cold rolled material for 1, 2, and 5 minutes at $623 \mathrm{~K}\left(350^{\circ} \mathrm{C}\right)$. To capture the partially recrystallized microstructure, a lower annealing temperature $[623 \mathrm{~K}$ $\left(350^{\circ} \mathrm{C}\right)$ ] was used to slow the recrystallization kinetics. The bulk texture of the material after full recrystallization at $623 \mathrm{~K}\left(350{ }^{\circ} \mathrm{C}\right)$ was found to be identical to that after annealing at $673 \mathrm{~K}\left(400{ }^{\circ} \mathrm{C}\right)$. The SRX mechanism of the material at $623 \mathrm{~K}\left(350{ }^{\circ} \mathrm{C}\right)$ is thus expected to be the same as that at $673 \mathrm{~K}\left(400{ }^{\circ} \mathrm{C}\right)$.

Bulk texture was measured by XRD using the Bruker D8 Discover diffractometer. $\{10 \overline{1} 0\},\{0002\},\{10 \overline{1} 1\}$, and $\{10 \overline{1} 2\}$ pole figures were measured and recalculated using the MTEX texture analysis package. ${ }^{[16]}$ Bulk texture pole figures presented here are all oriented with $\mathrm{RD}_{\mathrm{HR}}$ direction vertical and the $\mathrm{TD}_{\mathrm{HR}}$ direction horizontal.

Metallographic specimens were prepared for EBSD by the usual mechanical grinding and polishing followed by electropolishing in a 30 pet nitric acid 70 pct ethanol solution for 10 seconds at $12 \mathrm{~V}$. EBSD maps were acquired of the TCR material using an FEI Magellan Field Emission Gun Scanning Electron Microscope (FEGSEM) operated at $10 \mathrm{kV}$ with a step size of 0.1 $\mu \mathrm{m}$. All EBSD maps are presented with IPF coloring 


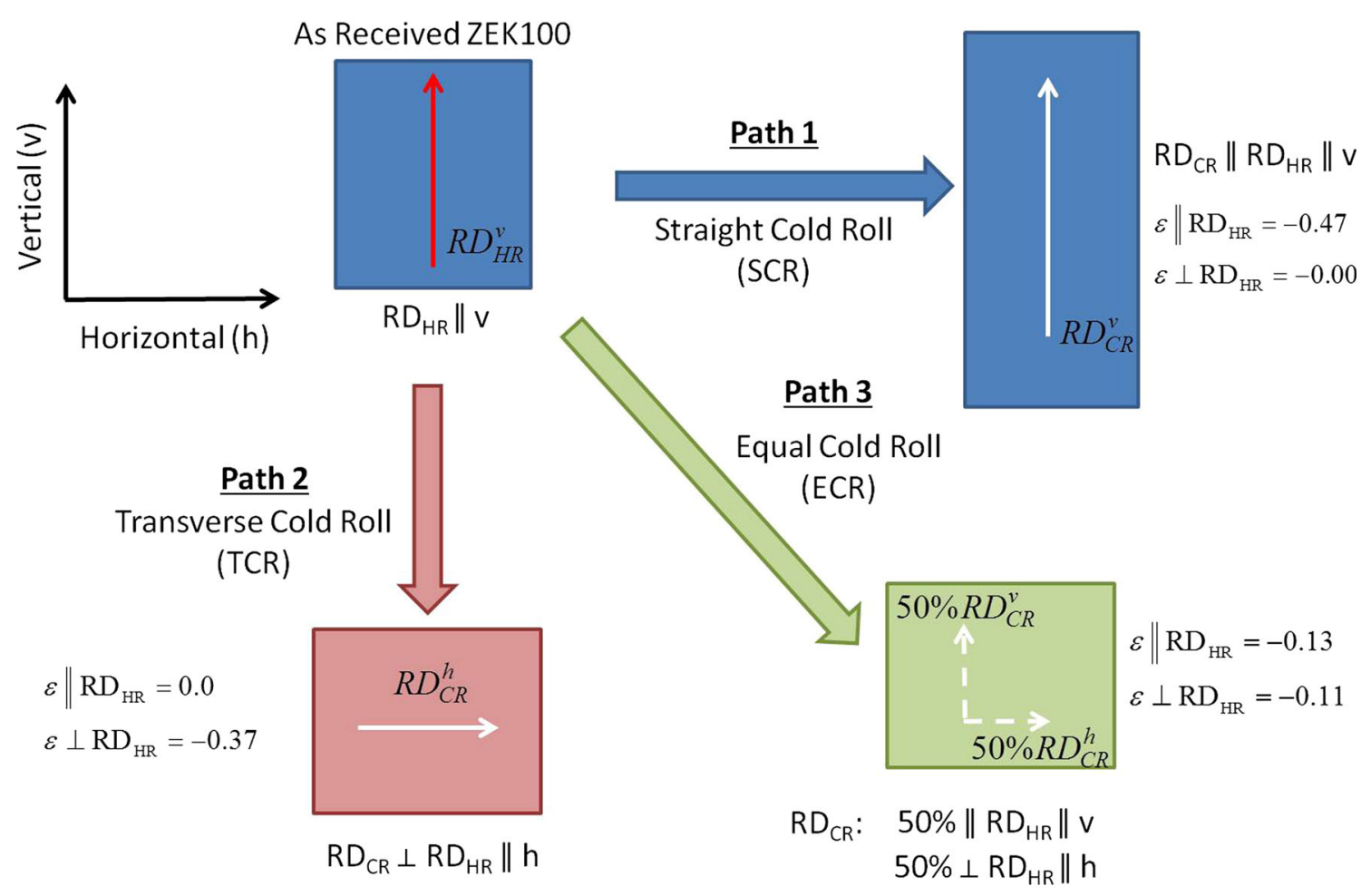

Fig. 1-Schematic showing the straight cold rolling, transverse cold rolling, and equal cold rolling processes. Red arrow indicates hot rolling direction of original material and white arrow cold rolling direction in each case. The strains imparted in each orientation are also shown (Color figure online).

Table I. Rolling Schedule for the Transverse Cold Rolling (TCR) and Straight Cold Rolling (SCR), Showing Cumulative True Strain Over Nine Passes

\begin{tabular}{lrr}
\hline Pass & TCR & SCR \\
\hline 0 & 0.00 & 0.00 \\
1 & -0.03 & -0.04 \\
2 & -0.06 & -0.07 \\
3 & -0.09 & -0.11 \\
4 & -0.14 & -0.16 \\
5 & -0.18 & -0.22 \\
6 & -0.22 & -0.29 \\
7 & -0.27 & -0.35 \\
8 & -0.32 & -0.41 \\
9 & -0.37 & -0.46 \\
\hline
\end{tabular}

with respect to the cold rolling direction of the final pass.

\section{DEFORMATION SIMULATIONS}

Visco-Plastic-Self-Consistent (VPSC) crystal plasticity modeling is a useful tool to simulate the three rolling processes and estimate deformation mode activity in each case. The code used in the present work is that developed at Los Alamos by Lebensohn and Tomé ${ }^{[17,18]}$ and has been proven for the simulation of magnesium deformation including slip and twinning. ${ }^{[19,20]}$ Note that the VPSC model considers only homogeneous
Table II. Cold Rolling Schedule for the Equal Cold Rolled ZEK100 (Reduction in Each Pass and Total True Strain)

\begin{tabular}{lccr}
\hline & $\mathrm{RD}_{\mathrm{CR}} \| \mathrm{RD}_{\mathrm{HR}}$ & $\mathrm{RD}_{\mathrm{CR}} \perp \mathrm{RD}_{\mathrm{HR}}$ & \\
Passes & 0.004 & & $\epsilon_{\mathrm{Total}}$ \\
\hline 1 & & -0.023 & -0.004 \\
2 & -0.011 & -0.032 & -0.038 \\
3 & & & -0.070 \\
4 & -0.015 & & -0.085 \\
5 & -0.027 & & -0.112 \\
6 & -0.029 & -0.052 & -0.159 \\
7 & -0.018 & & -0.211 \\
8 & -0.008 & & -0.245 \\
9 & -0.026 & -0.11 & \\
10 & -0.14 & & \\
11 & & &
\end{tabular}

deformation, and does not account for strain localization effects (e.g., shear banding).

The minimum parameter approach proposed by Hutchinson, Jain, and Barnett ${ }^{[21]}$ was adopted to determine the input parameters for each deformation system. In this approach, the same work hardening behavior is approximated for each slip system and a single microstructure constant is applied to scale the critical resolved shear stress (CRSS) values. This approximation is justified as hardening mechanisms will tend to act on all deformation systems. The model variables used in this study are presented in Table III, and these are broadly similar to those used by 
Table III. Parameters Used in the VPSC Model, Based on the Minimum Parameters Approach by Hutchinson et al. ${ }^{[21]}$

\begin{tabular}{lc}
\hline Parameter & Value (MPa) \\
\hline CRSS Basal $\langle a\rangle$ & 1 \\
CRSS Prism $\langle a\rangle$ & 46 \\
CRSS Pyram $\langle c+a\rangle$ & 160 \\
CRSS Compression Twin & 85 \\
CRSS Tension Twin & 7 \\
Microstructure Constant & 35 \\
$h_{0}$ & 1500 \\
$\tau_{1}$ & 70 \\
\hline
\end{tabular}

Hutchinson et al. $;^{[21]}$ however, the CRSS of pyramidal slip was increased from 63 to $160 \mathrm{MPa}$ to better reproduce experimental deformation textures seen in this work. Regardless of the exact CRSS value for pyramidal slip, it is the hardest mode to activate.

\section{RESULTS}

\section{A. Initial and Cold Rolled Microstructure}

Figure 2(a) shows an EBSD map (band contrast) of the starting material prior to cold rolling. The microstructure is largely recrystallized, and contains grains with a wide distribution of sizes, ranging from 5 to $50 \mu \mathrm{m}$. The average grain size (determined by mean linear intercept) is $12 \mu \mathrm{m}$. Boundaries with misorientations matching those of tensile, compression, and double twins are marked on the map. It can be seen there are very few twin boundaries identified in the initial material.

Figure 2(b) shows an EBSD band contrast map after straight cold rolling (higher magnification). A highly heterogenous microstructure is observed, characterized by bands of intense deformation. Indexing was not possible in the most heavily deformed regions within these bands; unindexed regions appear black. Again, special boundaries corresponding to twins are highlighted. Both compression $(\{10 \overline{1} 1\})$ and double $(\{10 \overline{1} 1\}-\{10 \overline{1} 2\})$ boundaries are seen to be dominant, with very few of the low CRSS $\{10 \overline{1} 2\}$ twins. A high fraction of the boundary identified as double twins is in the very heavily deformed regions, where limited indexing and the very fine scale of the microstructure make it hard to unambiguously identify whether this is really twinned material. It is also important to note that many of the grains are not twinned, including the largest grains, and the overall twin volume fraction is very small. This point is consistent with the VPSC modeling, as shown later.

\section{B. Bulk Textures After Cold Rolling and Recrystallization}

The bulk textures of the deformed and fully recrystallized ZEK100 after each rolling process are presented in Figure 3. The RD and TD in each figure relate to the hot rolling and transverse directions of the original sheet, respectively. The texture of the as-received fully recrystallized sheet is given in Figure 3(a). This texture shows the characteristic split basal texture of ZEK100, forming two lobes split by $\approx 30$ deg toward the TD.

The as-rolled texture of the material after each cold rolling schedule is presented in Figures 3 (b, d, and f). In each case, the material behaves typically for magnesium with basal poles rotating toward the ND. A texture split is still evident, but the deviation from the ideal basal orientation $(\approx 10 \mathrm{deg})$ is much less than in the starting material. The basal pole figure of the SCR material is split toward the RDCR (parallel to RDHR) direction, Figure 3(b). The as-rolled TCR and ECR basal texture is split toward the TDHR (which corresponds to RDCR of the final rolling pass), Figures 3(d) and (f). In the TCR as-rolled material, although the basal poles are split toward the TDHR direction, the spread in this direction is reduced. In all cases, the prismatic pole figures show a weak texture; there is evidence in the prismatic pole figure of the SCR material for a weak $\{11 \overline{2} 0\} \|$ RDHR texture.

Annealing for 60 minutes at $673 \mathrm{~K}\left(400{ }^{\circ} \mathrm{C}\right)$ fully recrystallizes each alloy. The recrystallized textures are shown in Figures 3(c, e, g). The texture for the SCR material (Figure 3(c)) is very similar to that of the parent hot rolled sheet (Figure 3(a)) as recrystallization has reproduced the $\mathrm{TD}_{\mathrm{HR}}$ spread in the basal pole figure. The recrystallized texture of the TCR material is shown in Figure 2(e). In this case, recrystallization has produced a similar split in the basal texture; however, it is rotated by 90 deg with respect to the hot rolling direction, Figure 3(a). Although rotated by 90 deg, both the SCR and TCR material have formed the Zn-RE recrystallization texture with a spread in the basal poles toward the cold rolling TD. It is notable that in the TCR material, the texture split observed in the original hot rolled plate has been completely replaced by a texture split rotated by 90 deg (i.e., basal poles rotated toward the cold rolled TD, which corresponds to the hot rolled $\mathrm{RD}$ ).

The recrystallized texture of the ECR material is shown in Figure $3(\mathrm{~g})$. In contrast to the SCR and TCR material, recrystallization after ECR does not produce a significant change in the texture components observed, but only in the texture intensity. The recrystallization texture in ECR material is best described as a weakened deformation texture, where the as-rolled split basal texture of Figure 2(f) has simply weakened. Notably the split in the recrystallized basal poles after ECR is $\approx 10$ deg, which is significantly less than the $\approx 30 \mathrm{deg}$ split observed in the other recrystallized materials.

\section{Modeling Deformation}

The VPSC model was used to simulate each rolling process and produce predicted deformation textures together with slip system activities in each case. The results are shown in Figure 4. The main qualitative features of the deformation textures are reasonably well reproduced: the simulated basal pole figure for SCR, Figure 4(a), contains two intense lobes split toward the $\mathrm{RD}_{\mathrm{CR}}\left(\mathrm{RD}_{\mathrm{HR}}\right)$ and the diffuse spreading of the texture 

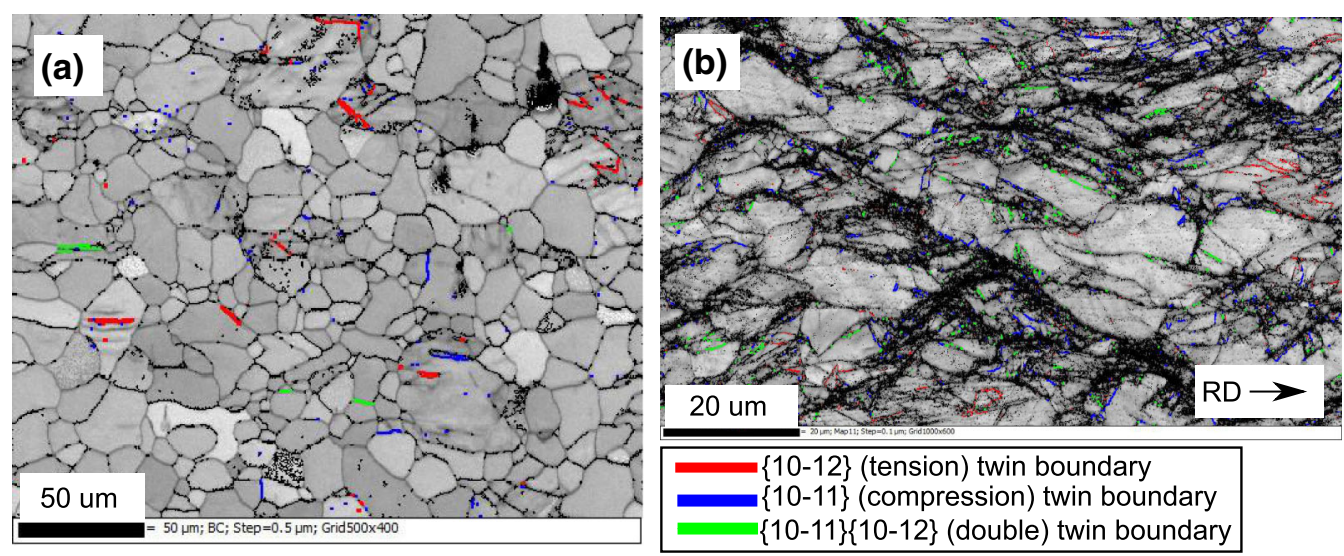

Fig. 2-EBSD band contrast maps (a) initial as-received (hot rolled) sheet (b) after straight cold rolling (SCR). Twin boundaries for the dominant twinning modes are marked as indicated.

(a)

Recrystallised Hot Rolled Texture

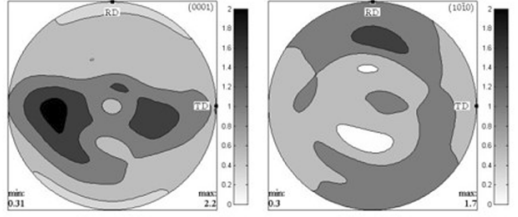

As Cold Rolled

(b)

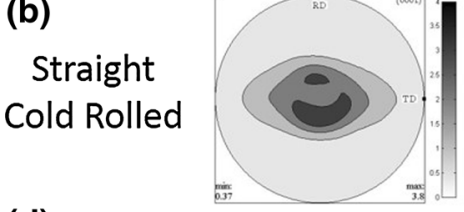

(d)

Transverse

Cold Rolled

(f)

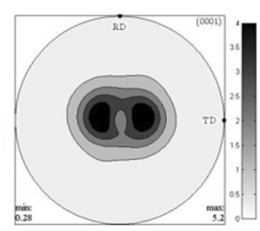

Equal Cold Rolled

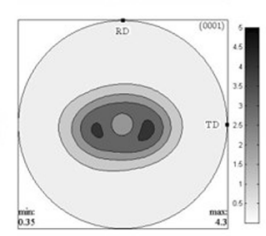

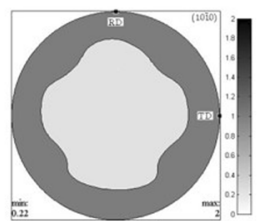
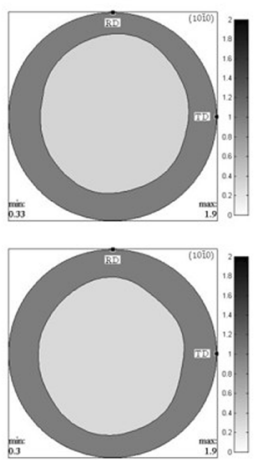

(c)

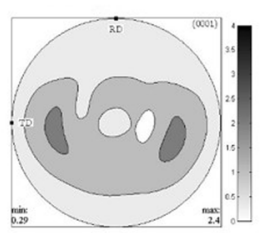

(e)

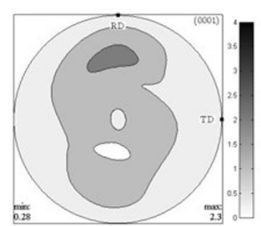

(g)

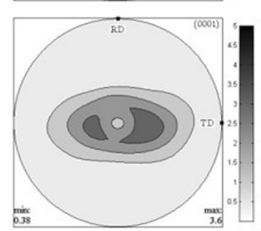

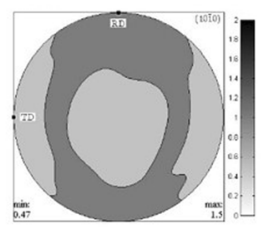

Straight Cold Rolled

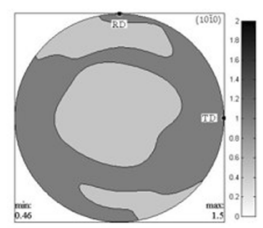

Transverse Cold Rolled

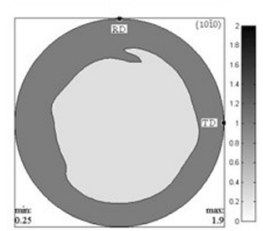

Equal Cold Rolled

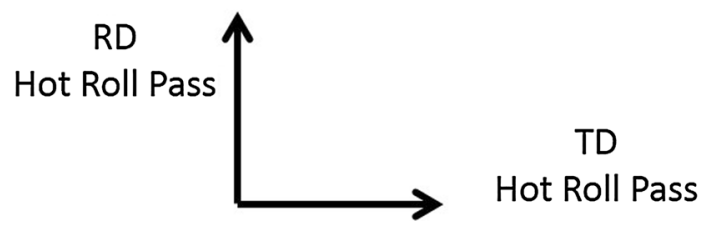

Fig. 3- $\{0001\}$ and $\{10 \overline{1} 0\}$ pole figures showing $(a)$ the as-received hot rolled and recrystallized ZEK100 texture. Together with the as-cold rolled $(b, d, f)$ and fully recrystallized $(c, e, g)$ textures of ZEK 100 after 60 minutes of annealing at $673 \mathrm{~K}\left(400{ }^{\circ} \mathrm{C}\right)$, following straight cold rolling, transverse cold rolling, and equal cold rolling. The RD and TD orientations indicated are of the original hot rolled directions in all cases.

in the $\mathrm{TD}_{\mathrm{HR}}$, which is observed experimentally in Figure 3(b). The model also predicts a relatively strong $\{11 \overline{2} 0\} \| \mathrm{RD}_{\mathrm{HR}}$ texture component in the prismatic pole figure, the beginnings of which can be seen in
Figure 3(b). The simulated deformation textures of TCR and ECR are in similarly good agreement with experimental results: TCR simulations reproduce a split in the TD, but a reduced spread in this direction 
Figure 4(b), as observed experimentally in Figure 3(d), and ECR simulations reproduce a diffuse spread of orientations about the TD, Figure 4(c), which is observed experimentally in Figure 3(e).

The activities of each deformation mode are shown in Figures 4(d) through (f). As expected in magnesium, basal slip is the dominant deformation mode in all cases and contributes strongly to the strengthening of basal textures. The contribution of prismatic slip is strongly sensitive to the direction of cold rolling, with high prismatic slip activity predicted during SCR and low prismatic slip during TCR. The change in prismatic slip activity is also observed in ECR with high levels of prismatic slip predicted when the cold rolling direction is parallel to the hot rolling direction and low prismatic slip activity when perpendicular to it. The overall percentage activity, or percentage of strain, accommodated by each deformation mode during the three deformation processes is plotted in Figure 5. This shows that the ECR schedule is predicted to have basal, prismatic, pyramidal slip and tension twin activities which are between those predicted for the SCR and TCR schedules. This may be significant as increased non-basal slip is often cited as a critical factor in nucleating $\mathrm{Zn}$-RE textures.

\section{Texture Development in Transverse Cold Rolled Material}

As demonstrated, the transverse cold rolled (TCR) material produced a split in basal pole alignment (texture) that was completely reorientated (rotated by $90 \mathrm{deg}$ ) compared with the texture split in the original hot rolled plate after recrystallization. It is therefore useful to study the texture evolution in this material in an attempt to isolate the source of the texture change and the role played by the deformation structure compared with the recrystallization behavior. Note that as Figure 3 shows, the split in basal pole alignment toward the transverse direction (of the final cold rolling pass) clearly occurred during recrystallization and was not detectable in the bulk pole figure for the deformed condition.

EBSD maps of the deformed and partially recrystallized TCR material are shown in Figure 6. In the as-cold rolled condition, Figure 6(a), the microstructure contains slip bands and the beginnings of shear bands where deformation has been concentrated. These regions appear as black lines on the map, where severe deformation has prevented indexing of the Kikuchi patterns. During annealing, recrystallization begins in these regions as a very fine distribution of grains, shown in Figure 6(b). As recrystallization progresses, the recrystallized grains grow larger and begin to consume the microstructure outside the severely deformed regions, Figure 6(d).

The recrystallized grains can be further broken down by grain size. Figure 7 shows grains separated into small grains, with sizes less than $1 \mu \mathrm{m}$, and large grains, with sizes greater than $1 \mu \mathrm{m}$. In the case of the as-rolled material, the large grain population also includes the deformed grains. In the case of the annealed material, only recrystallized grains (grains with internal misorientations $<1$ deg are shown.

The textures are also plotted for each of these populations. In all cases, the small grains are aligned more closely to the ideal basal texture orientation, with a slight split basal texture toward the cold rolling direction. It is only the large grains that have orientations spread in the TD. With longer annealing times, these grains become increasingly dominant, leading to the texture seen in the fully recrystallized condition. This evolution in texture during recrystallization is gradual and progressive; it is clear that in the early stages of recrystallization, there are new grains formed with basal poles spread toward both the TD and RD (as is observed in non-RE containing $\mathrm{Mg}$ alloys). It is only as recrystallization proceeds that the grains with the characteristic spread in basal pole orientations toward the TD become dominant, which is (apparently) unique to $\mathrm{Mg}-\mathrm{Zn}-\mathrm{RE}$ and related alloys (e.g., $\mathrm{Mg}-\mathrm{Zn}-\mathrm{Ca}$ ).

\section{DISCUSSION}

The results of this study are consistent with previous investigations of texture evolution during recrystallization in Mg-Zn-(RE,Ca) alloys. (e.g., References 4 and 10-13) In the previous work, unidirectional hot rolling was used to deform the material, rather than cold deformation used here. In this work, it was demonstrated that in the deformed state, the spread of basal poles with respect to the normal direction is typical for a non-RE containing magnesium alloy. It is only during recrystallization that the TD spread emerges as grains in this orientation persist or grow replacing deformed grains spread in other orientations. The stored energy in the hot rolled material used for previous studies was less than in the current cold rolled material, and the material used in earlier work did not necessarily fully recrystallize on annealing.

By changing the strain path, as in the present study, it is possible to clearly separate the influence of alloying and dislocation activity/strain localization and thus gain a better insight into the mechanisms controlling the unusual texture evolution seen in these alloys. The strain paths chosen in this study were designed to activate different levels of basal and prismatic slip. In addition, changing the rotation of the workpiece between rolling passes will lead to differences in shear band behavior.

The formation of RE textures is often attributed to rare earth additions changing slip system activity, in particular increased non-basal slip. Here, it has been shown that after both SCR and TCR, ZEK100 recrystallizes to produce the Zn-RE texture component where the basal texture is split toward the TD. Crystal plasticity modeling predicts almost equal basal and prismatic slip activities after SCR, while TCR is expected to be accommodated by $\approx 65$ pct basal slip and only 10 pet prismatic slip, Figure 5. Pyramidal slip accounts for only 5 and 12 pct of slip system activity in each process, respectively. The ECR material, which is predicted to have basal, prismatic and pyramidal slip system activities between the extremes of SCR and $\mathrm{TCR}$, did not produce the $\mathrm{Zn}-\mathrm{RE}$ recrystallization 
SCR
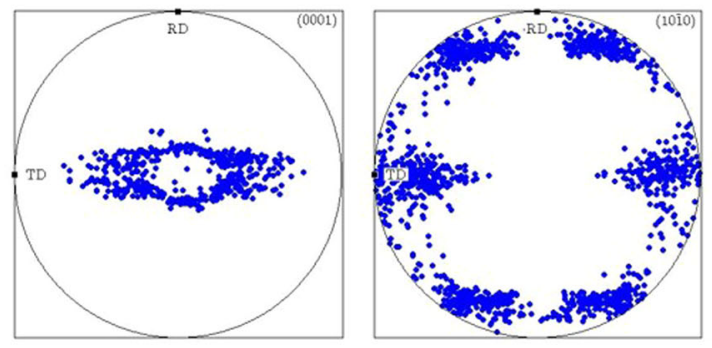

(a)

TCR
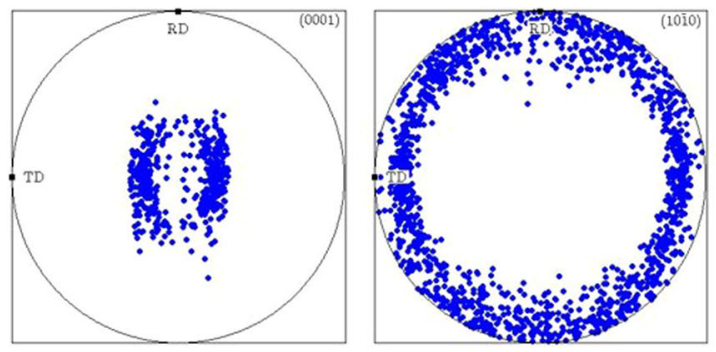

(b)

\section{ECR}
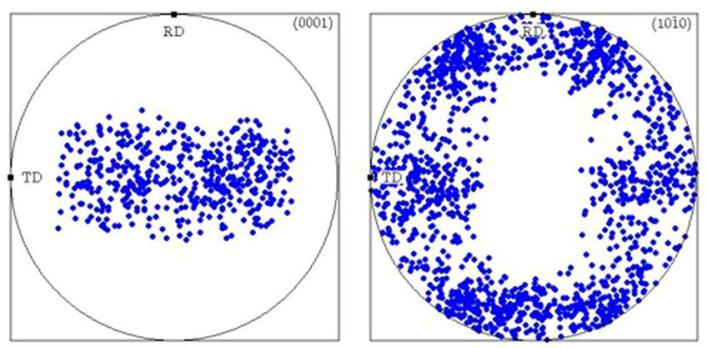

(c)

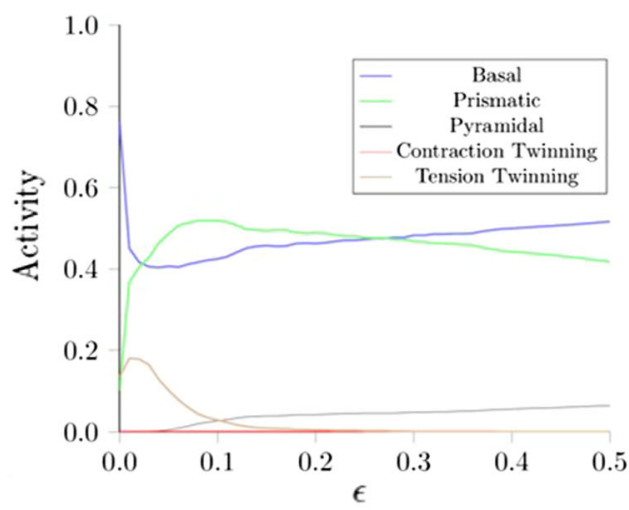

(d)

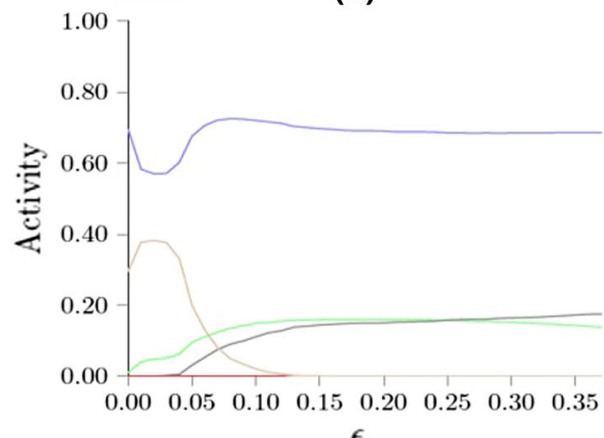

(e)

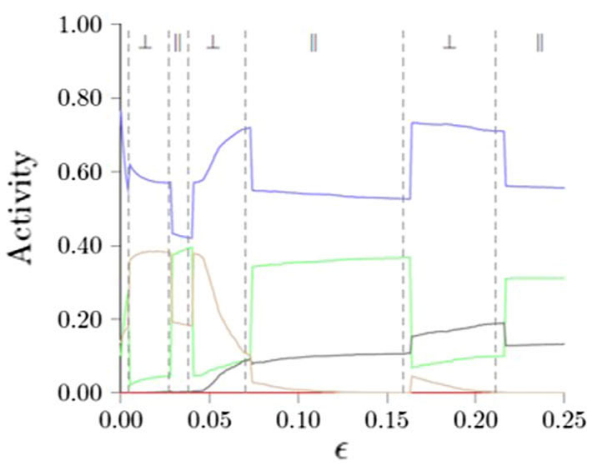

(f)

Fig. $4-\{0001\}$ and $\{10 \overline{1} 0\}$ pole figures showing the results of VPSC crystal plasticity model simulations of the cold rolling of ZEK100 under (a) SCR, $(b)$ TCR, and $(c)$ ECR conditions. Plots of the activities of each slip system are also included $d$ through $f$ ).

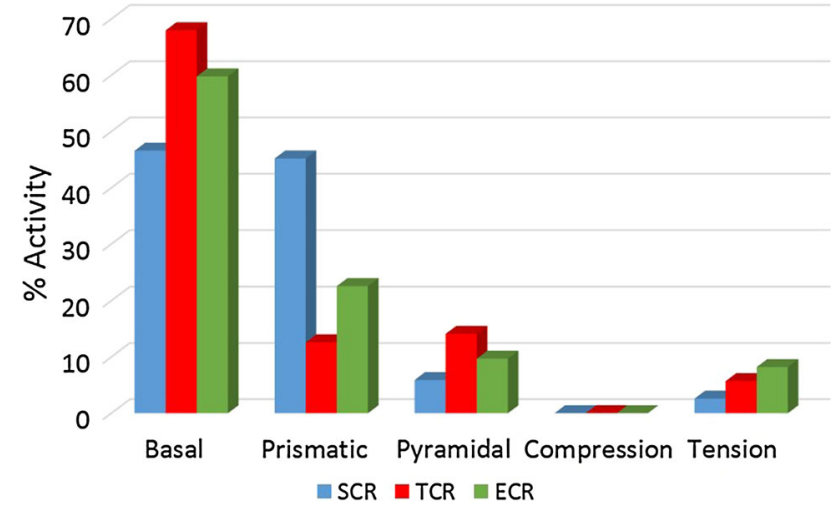

Fig. 5-Percentage activities of each deformation mode during straight, transverse, and equal cold rolling (SCR, TCR, and ECR) as predicted by the VPSC model. texture. This suggests that the formation of the distinctive $\mathrm{Zn}-\mathrm{RE}$ texture during recrystallization is not simply due to homogeneous differences in dislocation activity (i.e., number of each type of dislocation). It is clear that deformation inhomogeneity (e.g., shear banding), which is not accounted for in the VPSC model, is likely to play an essential role in producing the $\mathrm{Zn}-\mathrm{RE}$ texture split. Figure 8 shows EBSD maps of both the TCR and ECR material rolled to similar levels of strain. The persistent bands of local high deformation indicated by the unindexed (black) regions in the TCR material are not seen in the ECR material. It is from these bands of locally high deformation that the grains producing the Zn-RE texture split emerge.

The texture change effect in $\mathrm{Mg}-\mathrm{Zn}-\mathrm{Ca}$ alloys after cold deformation has also previously been attributed to changes in twinning behavior. ${ }^{[15]}$ In this case, it was 


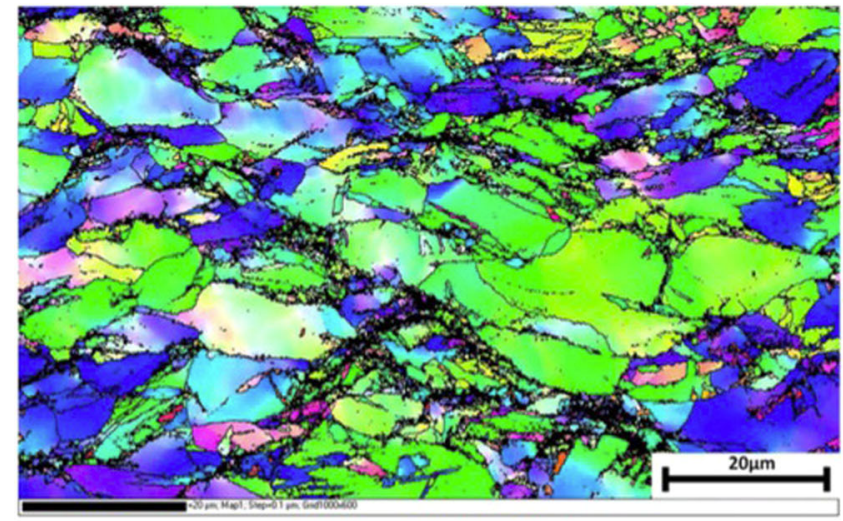

(a) As Cold Rolled

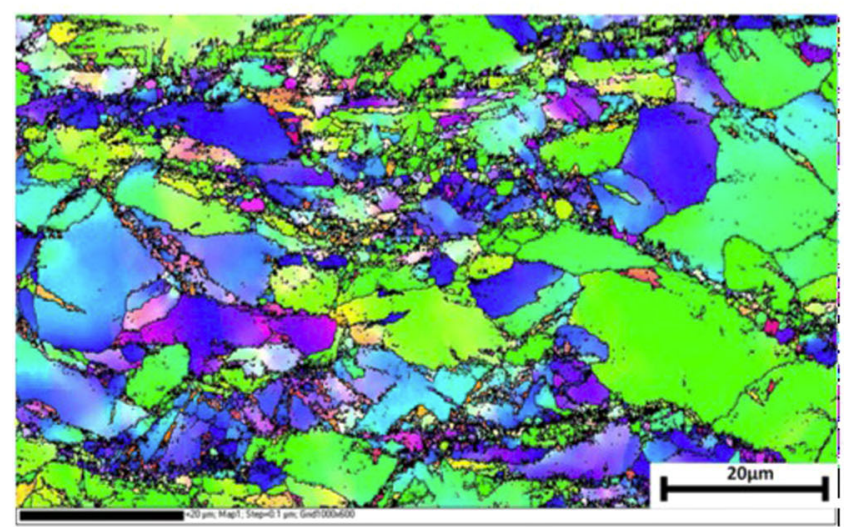

(c) $2 \mathrm{~min}$ at $623 \mathrm{~K}\left(350^{\circ} \mathrm{C}\right)$

ND

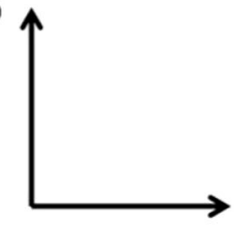

Cold Roll RD

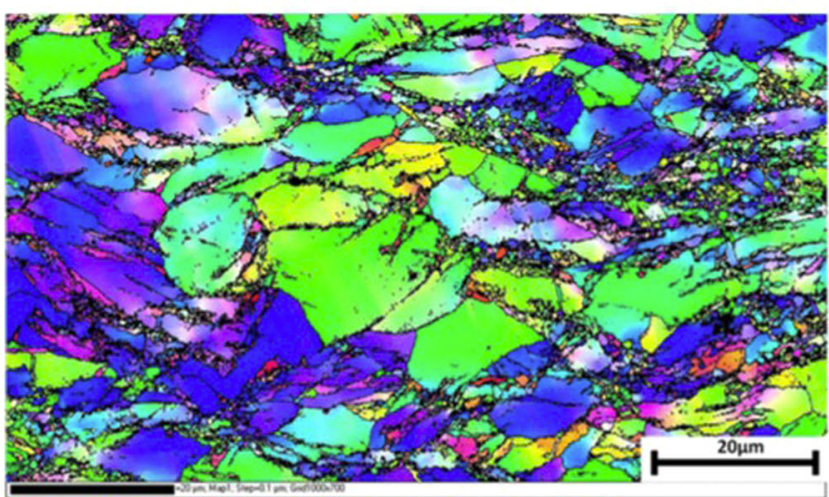

(b) $1 \mathrm{~min}$ at $623 \mathrm{~K}\left(350^{\circ} \mathrm{C}\right)$

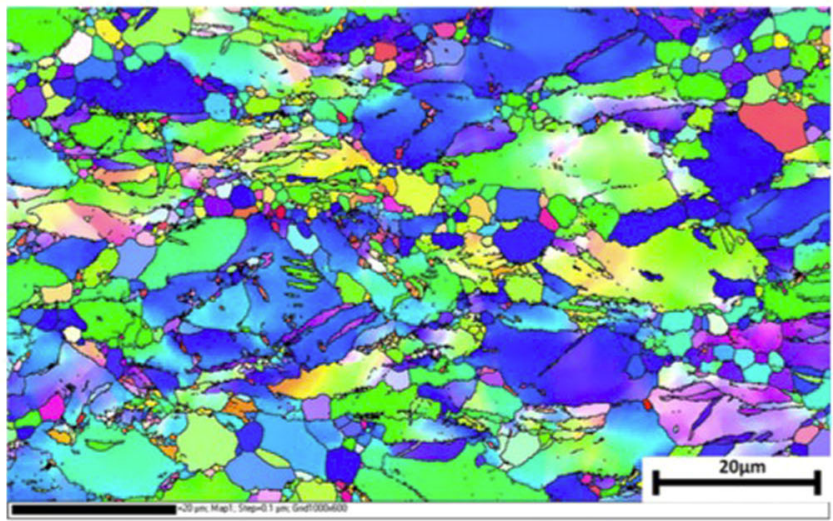

(d) 5 min at $623 \mathrm{~K}\left(350^{\circ} \mathrm{C}\right)$

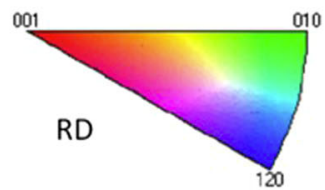

Fig. 6-EBSD maps of the transverse cold rolled ZEK100 in $(a)$ the as-rolled condition, $(b)$ annealed for 1 min, $(c) 2$ min, and $(d) 5$ min at $623 \mathrm{~K}\left(350^{\circ} \mathrm{C}\right)$. The maps are in IPF coloring relative to the cold rolling RD.

argued that the presence of $\mathrm{Zn}$ and $\mathrm{Ca}$ acts to suppress twin growth, leading to the formation of more twin variants within a grain. Recrystallization occurs within these twins, and the larger number of variants in the $\mathrm{Mg}-\mathrm{Zn}-\mathrm{Ca}$ case leads to a weaker and greater spread in recrystallization texture. This argument only applies when the volume fraction of twins is high. ${ }^{[15]}$ As the EBSD maps of the as-cold rolled material demonstrate, in the present case the volume fraction of twins is small $(<5$ pct) and it is shear bands (which may contain twins) that provide the most potent sites for recrystallization. Therefore, the explanation for the recrystallization textures observed in the present work is clearly different from that reported in Reference 15.

These results point to a complex relationship between slip system activity, shear band formation, and the resulting recrystallization texture. The evolution of the unique $\mathrm{Zn}$-RE texture is gradual, and can be observed more clearly by examining the EBSD data of Figure 7. Here recrystallization is shown to be largely confined to regions of concentrated deformation in the TCR material. At the early stages of deformation, a very large population of recrystallized grains with non-RE orientations can be detected, where the basal poles are slightly split toward the RD of the sheet. Despite the large numbers of these grains, during the early stages of static recrystallization grains with the $\mathrm{Zn}-\mathrm{RE}$ orientation grow largest and dominate the non-RE gains in the shear bands, even before the majority of deformed grains have recrystallized. It is interesting to compare these results with previous studies of recrystallization in hot rolled $\mathrm{Mg}-\mathrm{Zn}-\mathrm{RE}(\mathrm{Ca})$ alloys. ${ }^{[4,10-13]}$

These studies have also emphasized the importance of recrystallization in developing the $\mathrm{Zn}$-RE texture. They have also shown that in the early stages of recrystallization, there is no strong preference for grains split or 


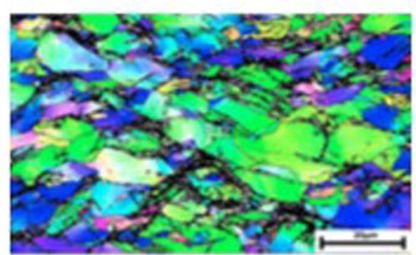

Larger than $1 \mu \mathrm{m}$
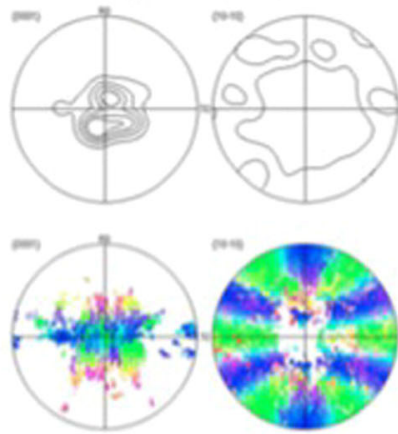

(a) As Rolled

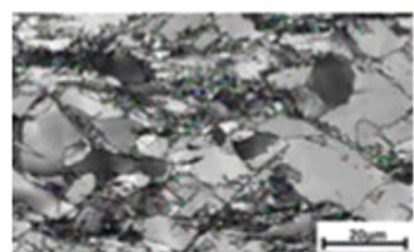

Smaller than $1 \mu \mathrm{m}$
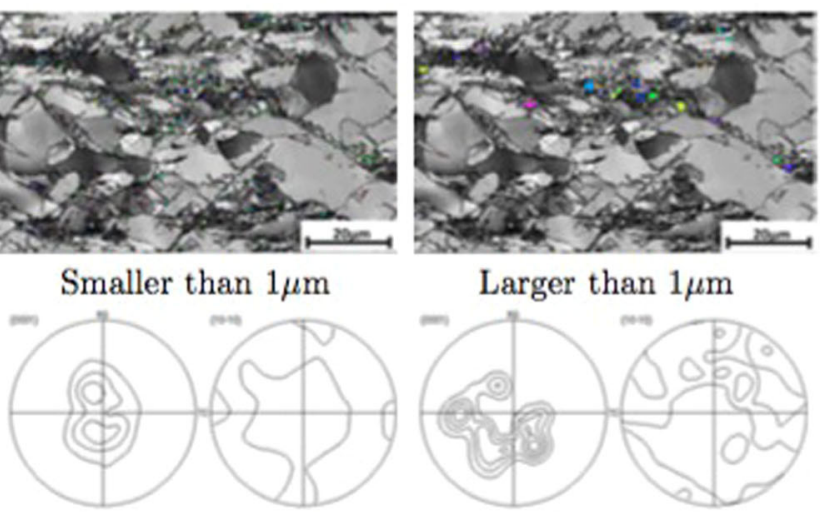

Larger than $1 \mu \mathrm{m}$
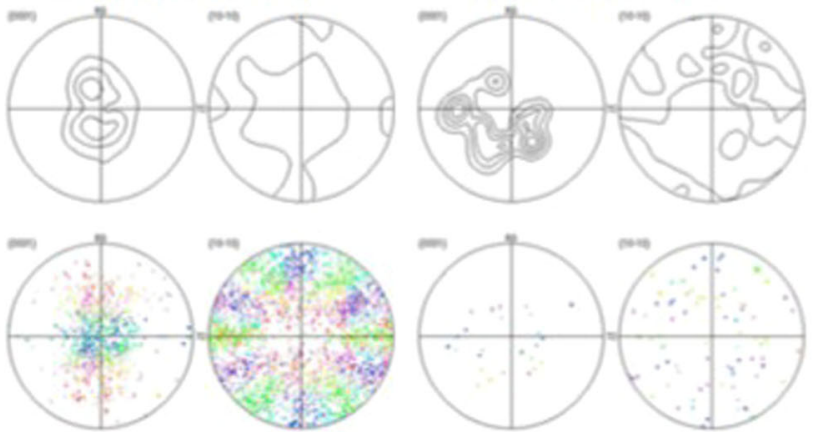

(c) $2 \mathrm{~min}$ at $623 \mathrm{~K}\left(350^{\circ} \mathrm{C}\right)$

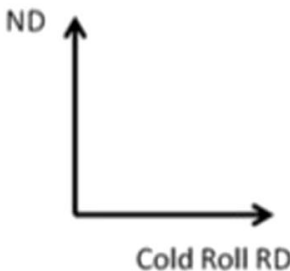

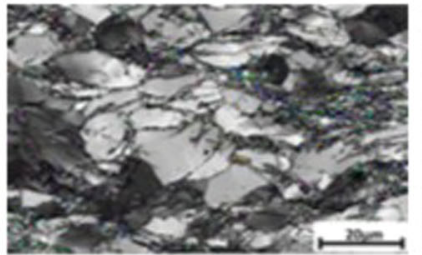

Smaller than $1 \mu \mathrm{m}$

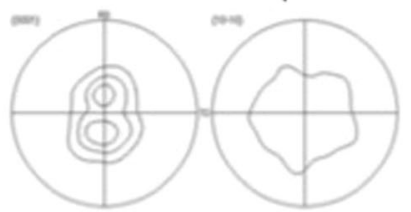

arger than $1 \mu \mathrm{m}$
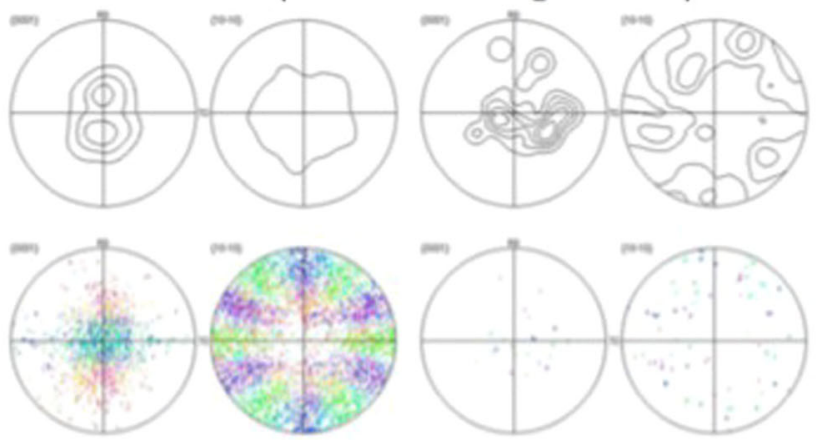

(b) $1 \mathrm{~min}$ at $623 \mathrm{~K}\left(350^{\circ} \mathrm{C}\right)$
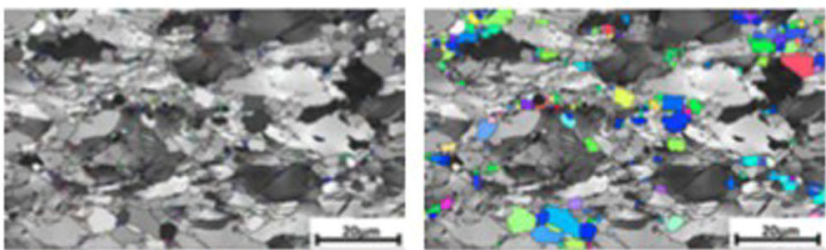

Smaller than $1 \mu \mathrm{m}$

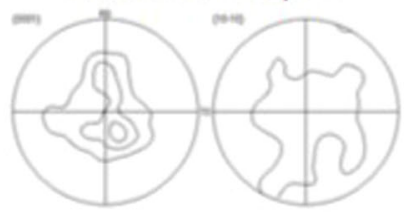

Larger than $1 \mu \mathrm{m}$
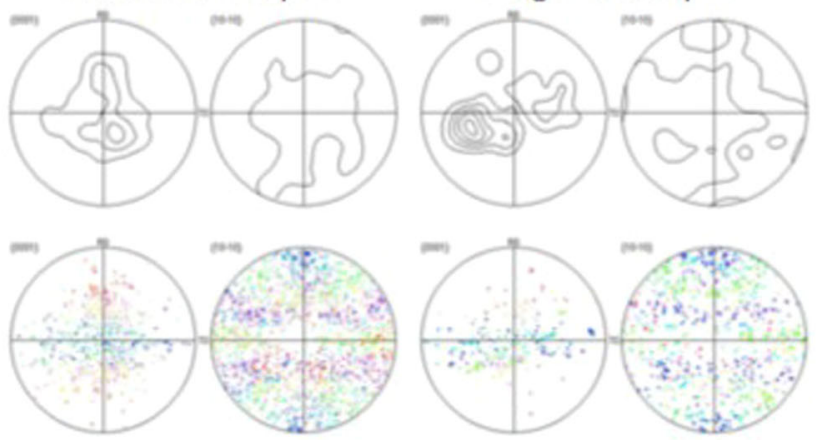

(d) $5 \mathrm{~min}$ at $623 \mathrm{~K}\left(350^{\circ} \mathrm{C}\right)$

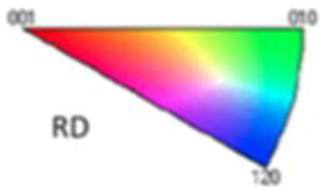

Fig. 7-Separating grains into small and large sizes, greater than or smaller than $1 \mu \mathrm{m}$. (a) As-rolled (all grains), $(b$ through $d)$ recrystallized grains only (grains with less than $1 \mathrm{deg}$ internal misorientation) (b) annealed for $1 \mathrm{~min}$, (c) $2 \mathrm{~min}$, (d) $5 \mathrm{~min}$ at $623 \mathrm{~K}\left(350{ }^{\circ} \mathrm{C}\right.$ ). The maps are in IPF coloring relative to the cold rolling RD.

spread toward the TD (the Zn-RE texture), and this only emerges gradually as the recrystallized fraction increases. It was also noted in these studies (as in the present case) that this initial recrystallization stage is rapid at typical annealing temperatures, and can be complete after a few minutes. The role of shear bands in producing the TD spread component was also noted previously. ${ }^{[4,10,13]}$ In studies of hot rolled material, it was suggested that deformed grains with orientations spread toward the TD are more resistant to recrystallization 


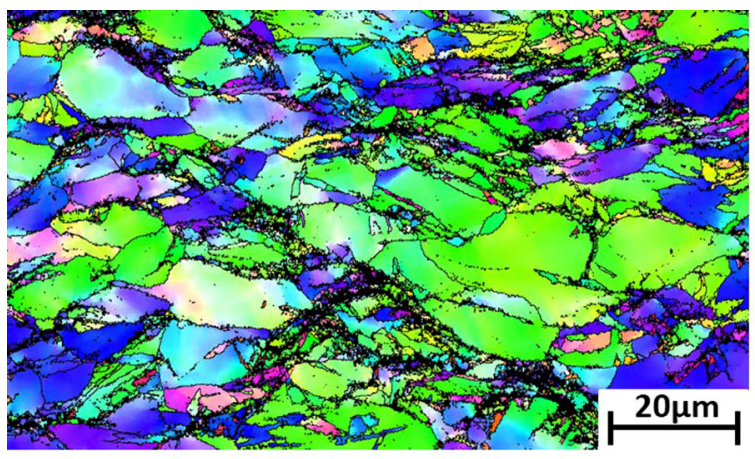

(a) TCR As Rolled

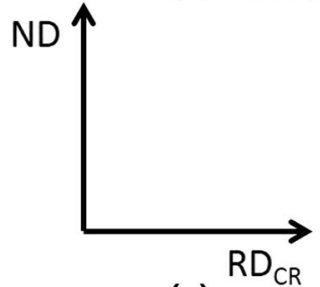

(c)

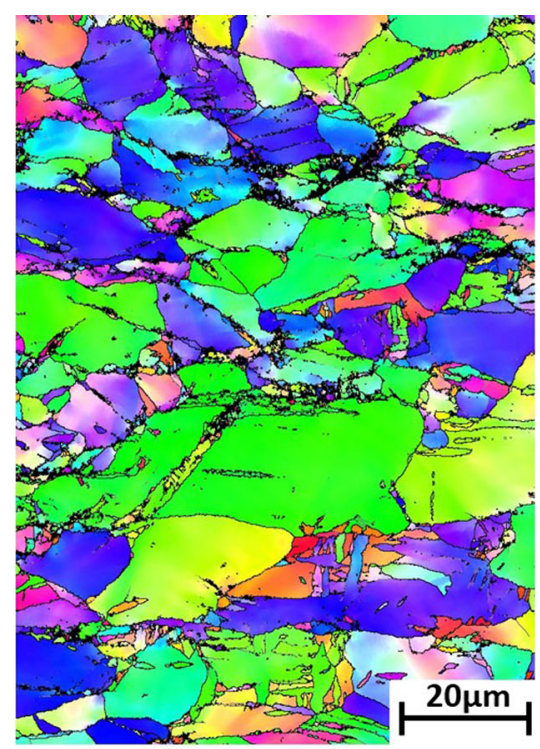

(b) ECR As Rolled

Fig. 8- (a) ZEK in the as-rolled condition after TCR to $\varepsilon=-0.37$ and $(b)$ ZEK100 in the as-rolled condition after ECR to $\varepsilon=-0.24$. $(c)$ Indicates the orientation of the figure; note that due to the $90 \mathrm{deg}$ rotations in (b) $\mathrm{RD}_{\mathrm{CR}}$ also corresponds to $\mathrm{TD} \mathrm{CR}_{\mathrm{C}}$ in 50 pct of passes.

and grow consuming grains in other orientations, ${ }^{[10]}$ i.e., in this case the TD spread grains are thought to be remnants of the deformation structure, which are recovered but not recrystallized. In the present work, cold rolling will have suppressed dynamic processes during deformation, and it is clear that the TD spread grains become dominant largely through recrystallization. However, even in the as-rolled material, small grains with a spread in the TD are already present in the deformed microstructure, as highlighted in Figure 9. These grains may already have a growth advantage due to recovery, bearing in mind there is likely to be a significant temperature increase in the heavily deformed shear bands, even during cold rolling.

One plausible explanation that is consistent with all the experimental results is that grains spread in the TD are able to recover faster during annealing than those in other orientations. ${ }^{[10]}$ They thus acquire a lower stored energy than surrounding grains in other orientations and will grow preferentially. It is clear that in the cold rolled material, as studied here, the TD spread orientations emerge from the shear bands, which are therefore a pre-requisite for this texture spread to be seen in the fully recrystallized material. If the strain path is changed to prevent the emergence of persistent shear bands, as in the ECR material, no distinct split in the basal texture is produced on annealing.

\section{CONCLUSIONS}

A commercial Mg-Zn-RE alloy (ZEK100) hot rolled sheet has been cold rolled under three different strain path regimes followed by annealing. Cold rolling parallel to the hot rolling direction (straight cold rolling,
SCR) or transverse to the hot rolled direction (transverse cold rolling, TCR) led to distinct shear banding in the deformed state. Rotating the sheet between cold rolling passes (equal cold rolling, ECR) suppressed the formation of shear bands. After cold rolling, the texture of the original hot rolled sheet sharpened toward a typical basal texture for all strain paths. A split in basal pole orientations was observed, rotated toward the rolling direction of the final cold rolling passes in each case.

On annealing, a fully recrystallized microstructure was formed. In the case of the SCR and TCR material, this was accompanied by a strong change in texture, in which the basal poles became broadly spread toward the transverse direction of the final cold rolling pass $(30$ deg spread). This unusual texture has previously noted for ternary $\mathrm{Mg}-\mathrm{Zn}-\mathrm{RE}$ and $\mathrm{Mg}-\mathrm{Zn}-\mathrm{Ca}$ alloys. In the case of the SCR material, this meant a texture was produced similar to that of the initial hot rolled sheet, whereas in the TCR sheet the split in texture was rotated by $90 \mathrm{deg}$. In the ECR sheet, a weakening of texture only was observed on recrystallization, with no distinct spread.

As confirmed by crystal plasticity calculations, these observations cannot be attributed to a homogeneous change in dislocation activity. Instead, the different shear band behavior induced by the different rolling schedules is essential to produce the difference in observed recrystallization textures. Consistent with previous studies of hot rolled material, it has been shown that the distinct spread of basal poles toward the transverse direction arises gradually during recrystallization as grains with this orientation grow preferentially to consume other orientations. 


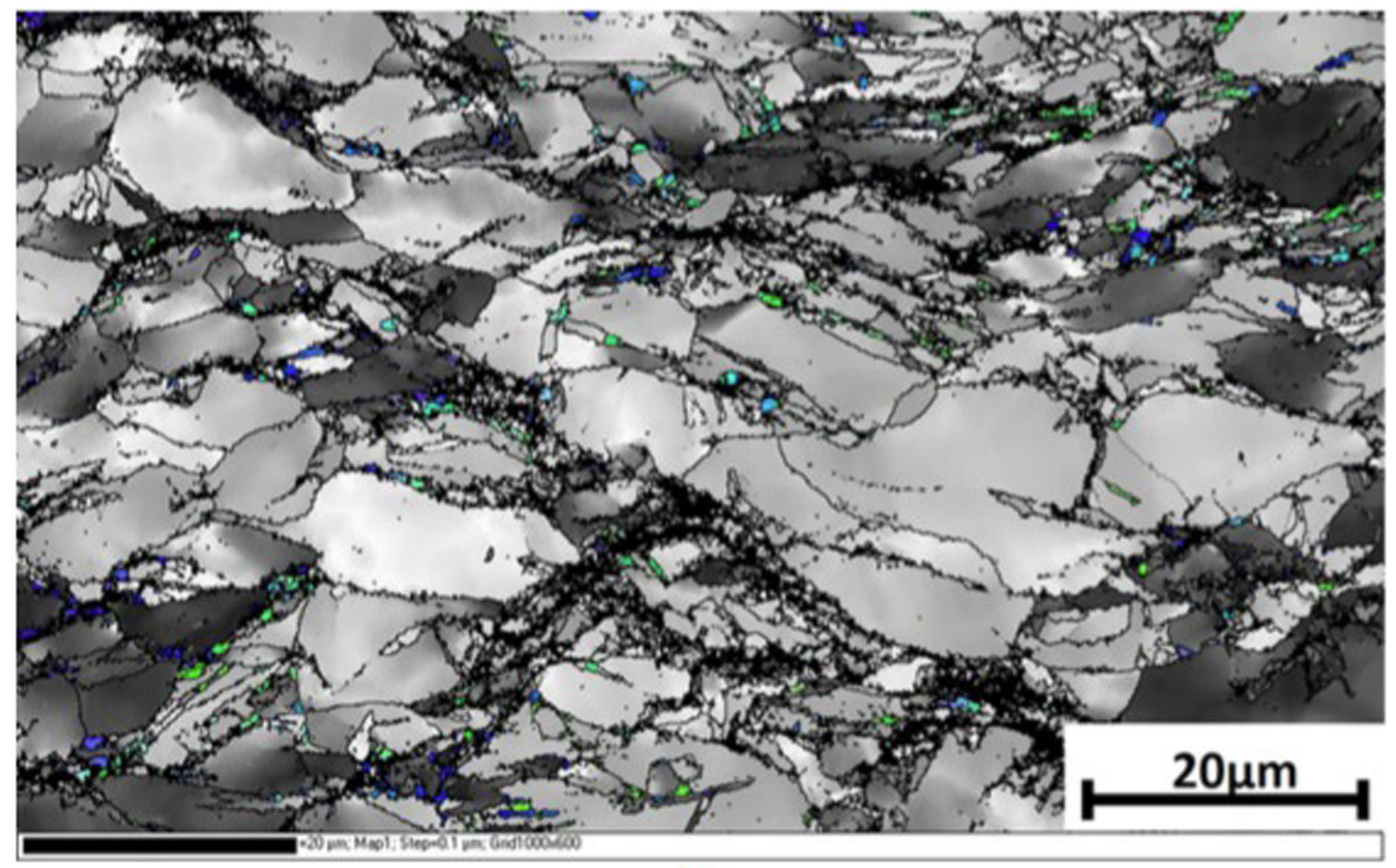

(a)

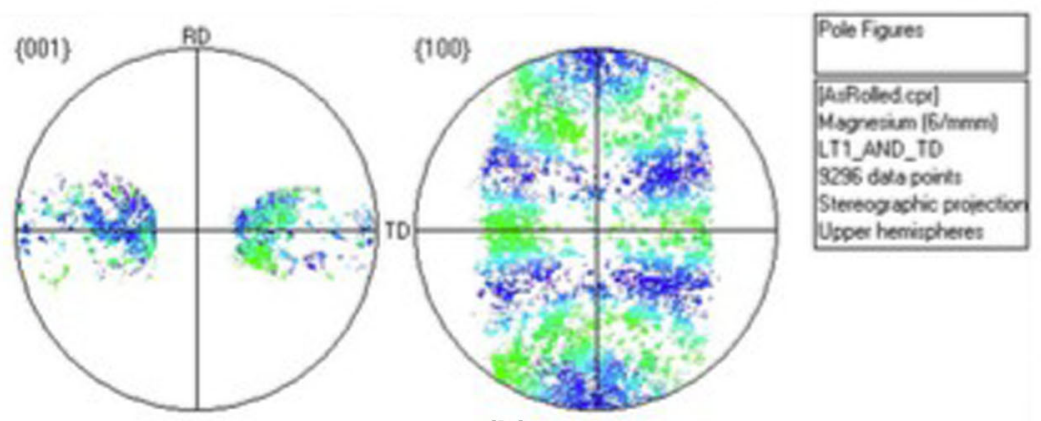

(b)

Fig. 9- (a) EBSD map of as transverse cold rolled ZEK100 with the $\mathrm{TD}_{\mathrm{CR}}$ orientations highlighted. (b) Pole figure indicated the TD orientations selected.

\section{ACKNOWLEDGMENTS}

The authors are grateful to Magnesium Elektron North America Inc. for provision of materials for this study. Thanks to Magnesium Elektron and EPSRC LATEST-2 programme Grant (EP/H020047/1) for financial support for this work. D. Griffiths is supported through the EPSRC Centre for Doctoral Training in Advanced Metallic Systems.

\section{OPEN ACCESS}

This article is distributed under the terms of the Creative Commons Attribution 4.0 International
License (http://creativecommons.org/licenses/by/4.0/), which permits unrestricted use, distribution, and reproduction in any medium, provided you give appropriate credit to the original author(s) and the source, provide a link to the Creative Commons license, and indicate if changes were made.

\section{REFERENCES}

1. B.L. Mordike: Mater. Sci. Eng. A, 2002, vol. 324, pp. 103-12.

2. K. Hantzsche, J. Bohlen, J. Wendt, K. Kainer, S. Yi, and D. Letzig: Scripta Mater., 2010, vol. 63, pp. 725-30.

3. N. Stanford, D. Atwell, A. Beer, C. Davies, and M.R. Barnett: Scripta Mater., 2008, vol. 59, pp. 772-75. 
4. J. Bohlen, M.R. Nürnberg, J.W. Senn, D. Letzig, and S.R. Agnew: Acta Mater., 2007, vol. 55, pp. 2101-22.

5. J.P. Hadorn, K. Hantzsche, S.B. Yi, J. Bohlen, D. Letzig, J.A. Wollmershauser, and S.R. Agnew: Metall. Mater. Trans. A, 2012, vol. 43A, pp. 1347-62.

6. J.P. Hadorn, T.T. Sasaki, T. Nakata, T. Ohkubo, S. Kamado, and K. Hono: Scripta Mater., 2014, vol. 93, pp. 28-31.

7. J.D. Robson: Metall. Mater. Trans. A, 2014, vol. 45A, pp. 3205-12.

8. M. Bugnet, A. Kula, M. Niewczas, and G.A. Botton: Acta Mater., 2014, vol. 79, pp. 66-73.

9. D. Griffiths: Mater. Sci. Tech., 2015, vol. 31, pp. 10-24.

10. J. Bohlen, J. Wendt, M. Nienaber, K.U. Kainer, L. Stutz, and D. Letzig: Mater. Charact., 2015, vol. 101, pp. 144-52.

11. I. Basu and T. Al-Samman: Acta Mater., 2014, vol. 67, pp. 116-33.

12. T. Al-Samman and X. Li: Mater. Sci. Eng. A, 2011, vol. 528, pp. 3809-22.
13. L.W.F. Mackenzie and M.O. Pekguleryuz: Scripta Mater., 2008, vol. 59, pp. 665-68.

14. P. Dobron, J. Balík, F. Chmelík, K. Illková, J. Bohlen, D. Letzig, and P. Lukáč: J. Alloys Compd., 2014, vol. 558, pp. 628-32.

15. Z.R. Zeng, M.Z. Bian, S.W. Xu, C.H.J. Davies, N. Birbilis, and J.F. Nie: Scripta Mater., 2015, vol. 108, pp. 6-10.

16. R. Hielscher and H. Schaeben: J. Appl. Crystall., 2008, vol. 41, pp. 1024-37.

17. R.A. Lebensohn and C.N. Tomé: Acta Metall. Mater., 1993, vol. 41, pp. 2611-24.

18. R.A. Lebensohn and C. Tomé: Mater. Sci. Eng. A, 1994, vol. 175, pp. 71-82.

19. S.R. Agnew and O. Duygulu: Int. J. Plast., 2005, vol. 21, pp. 1161-93.

20. H. Wang, B. Raeisinia, P.D. Wu, S.R. Agnew, and C.N. Tomé: Int. J. Solids Struct., 2010, vol. 47, pp. 2905-17.

21. B. Hutchinson, J. Jain, and M.R. Barnett: Acta Mater., 2012, vol. 60 , pp. 5391-98. 